DOI:10.5216/cab.v11i3.5945

\title{
FREQUÊNCIA DE ANTICORPOS ANTI-Toxoplasma gondii EM REBANHOS CAPRINOS DO MUNICÍPIO DE SÃO LUÍS, MA
}

\author{
Júlia Gleyci Soares, ${ }^{1}$ Maria Inez Santos Silva² E Vivian Magalhães Brandão ${ }^{3}$ \\ 1. Acadêmica do Curso de Medicina Veterinária da Universidade Estadual do Maranhão. \\ E-mail: julinha_soares@hotmail.com \\ 2. Mestranda da Universidade Estadual do Maranhão \\ 3. Orientadora e professora de Epidemiologia da Universidade Estadual do Maranhão.
}

\section{RESUMO}

O trabalho objetivou estimar a frequência de rebanhos caprinos soropositivos ao Toxoplasma gondii no município de São Luís, Maranhão, Brasil, através do método ELISA indireto (Enzime Linked Immunosorbent Assay). Utilizaram-se o programa Epi Info 3.5.1 e os Testes Qui-quadrado e Exato de Fisher, para análise dos dados. Verificou-se que, dos 92 soros analisados, 34 (36,95\%) eram soropositivos e $58(63,05 \%)$ soronegativos. Em relação às propriedades de rebanhos caprinos pesquisadas, verificou-se soropositividade em oito ( $80 \%$ ) das dez utilizadas no estudo. Das propriedades com condições de estocagem de alimento, 24 propriedades foram consideradas ruins e quatorze $(15,3 \%)$ foram soropositivas para T. gondii, verificando-se associação significativa $(\mathrm{p}<0,05)$. A exploração leiteira apresentou associação significativa $(p=0,0478)$.
A de corte mostrou percentual significativo: do total de dezenove animais, onze $(57,89 \%)$ foram soropositivos. Em relação ao tipo de alimento, verificou-se (14) 58,33\% de soropositividade para os animais submetidos à alimentação com forragem $(\mathrm{p}<0,05)$, considerando que o fornecimento apenas de forragem como fonte de alimentação oferece risco, por ser uma fonte de infecção por T. gondii. No que se refere ao destino do material abortado, que é fator relevante, constatou-se que nenhum dos produtores realiza o destino adequado para esse material, o que muitas vezes não elimina a presença do fator de risco, verificando-se soropositividade e associação significativa $(\mathrm{p}<0,05)$. Não se verificaram neste estudo diferenças significativas na frequência do $T$. gondii, com relação ao sexo e faixa etária dos caprinos.

PALAVRAS-CHAVES: Caprinos, frequência, São Luís, MA, Toxoplasma gondii.

\section{ABSTRACT}

\section{FREQUENCY OF ANTI-Toxoplasma gondii ANTIBODIES IN CAPRINE HERDS FORM THE MUNICIPALITY OF SÃO LUÍS, MA/BRAZIL}

The objective of this work was to assess the frequency of Toxoplasma gondii seropotive goat herds in the municipality of São Luís, Maranhão, Brazil. The detection of anti-T.gondii was performed by the serological indirect ELISA method (Enzyme Linked Immunosorbent Assay). The data were analyzed using Epi Info 3.5.1 and subjected to chi-square and Fisher's exact test. From 92 sera tested, 34 (36.95\%) were seropositive and 58 (63.05\%) seronegative. From 10 properties of goat herds surveyed in the municipality of São Luís, MA, seropositivity was found in eight
(80\%) of them. Regarding the conditions of storage of food, from 24 properties considered poor, $14(15.3 \%)$ were seropositive for $T$. gondii, with a significant association $(\mathrm{p}<0.05)$. Milk production also had significant association $(\mathrm{p}=0.0478)$, and beef production presented significant percentage: from 19 animals, 11 (57.89) were seropositive. As regards the type of food, (14) $58.33 \%$ of seropositivity was verified within the animals fed forage $(\mathrm{p}<0.05)$. The aborted material is also a relevant factor found in this study, considering none of the producers gave the appropriate destina- 
tion for this material. This behavior does not often eliminate the presence of the risk factor, then seropositivity and association $(\mathrm{p}$
$<0.05$ ) can be verified. No significant differences were observed in the frequency of $T$. gondii, related to gender and age of goats.

KEYWORDS: Frequency, goats, São Luís, (MA), Toxoplasma gondii.

\section{INTRODUÇÃO}

O Toxoplasma gondii é um protozoário, parasito intracelular obrigatório, pertencente ao Filo Apicomplexa, classe sporozoa, subclasse coccidia e ordem eucoccidia, que possui distribuição mundial, ocorrendo em diversas espécies homeotérmicas, incluindo o homem. É uma das zoonoses mais difundidas no mundo (ACHA \& SZYFRES, 1986).

O protozoário tem ciclo vital complexo, envolvendo felinos como hospedeiros definitivos e uma grande gama de hospedeiros intermediários, como os animais de sangue quente, incluindo o homem (DUBEY et al., 2003).

O T. gondii apresenta-se de três formas principais: os taquizoítos, encontrados nos órgãos, sangue e secreções de animais na fase aguda da enfermidade; os bradizoítos, nos tecidos (podem causar infecção latente ou crônica); e os oocistos, no intestino de felinos silvestres e do gato, exclusivamente (AMATO NETO et al., 1995).

A infecção por $T$. gondii pode se disseminar entre os animais e o homem, por meio dos mais variados mecanismos de transmissão como ingestão de oocistos eliminados junto às fezes de felídeos, que se disseminam pelo meio ambiente contaminando o solo, a água, os alimentos e locais de pastagem; a ingestão de cistos presentes nos tecidos e órgãos de animais infectados; o contato direto com secreções de animais infectados e mecanismos de transmissão congênita. Além destes, citam-se ainda a ingestão de hospedeiros transportadores de alimentos por eles contaminados e transfusão sanguínea (CAMARGO, 1995).

Este parasito, descrito desde o início do século passado (NICOLLE \& MANCEAUX, 1909), causa uma zoonose de grande relevância para a saúde pública e saúde animal, uma vez que a infecção gera grandes perdas econômicas, traduzidas em abortos, natimortos e alterações neonatais, em várias espécies (DUBEY, 1981).

Do ponto de vista epidemiológico, a toxoplasmose é uma enfermidade cosmopolita com distribuição influenciada por vários fatores tais como climáticos, socioeconômicos, tipo de contato com animais domésticos, costumes alimentares em relação ao consumo de carne (CORCUERA et al., 1981).

A caprinocultura representa um segmento importante para o Nordeste brasileiro. A região possui cerca de 93\% do rebanho nacional. O estado do Maranhão retém aproximadamente 400.000 cabeças de rebanho caprino (SIDRA, 2005), sendo que o município de São Luís possui 185 cabeças, distribuídos em 22 propriedades (AGED, 2007). Esse número é provavelmente maior, em razão da grande valorização na criação de caprinos em todo o Brasil. Portanto, é de fundamental importância o estudo das doenças que interferem na produção dos rebanhos caprinos, destacando-se, dentre essas, a toxoplasmose.

A primeira evidência de toxoplasmose em caprinos foi registrada por FELDMAN \& MILLER (1956), quando examinavam rebanhos de Nova York, nos Estados Unidos. Desde então, diversos inquéritos têm sido realizados em vários países, inclusive no Brasil, registrando soropositividade na espécie caprina (DUBEY, 1990).

As taxas de infecção apontadas para rebanhos caprinos no Brasil são variáveis e este comportamento deve-se principalmente ao teste sorológico utilizado, à região e à idade dos animais estudados (DUBEY, 1991). Em Minas Gerais, MACHADO \& LIMA (1987) apontam $36,8 \%$ de caprinos positivos em 46 propriedades estudadas, com taxa de $36,1 \%$ entre os rebanhos leiteiros e $11,4 \%$ nos animais de corte. GONDIM et al. (1999) verificaram $28,93 \%$ de caprinos positivos ao teste de aglutinação ao látex, em pesquisa realizada na Bahia.

Estudos de isolamento de parasitas viáveis de tecidos comestíveis, bem como de leite caprino (CHIARI \& NEVES, 1984) revelam a importância dessas espécies como fonte de infecção para o homem.

A interferência da presença do T. gondii na cadeia produtiva caprina e seu potencial zoonótico justificam conhecer a distribuição desse agente em populações caprinas, assim como da toxoplasmose como zoonose. Mais de $50 \%$ da população humana mundial acha-se infectada pelo $T$. gondii, com variações de acordo com as regiões e os costumes (PIZZI, 1997). 
Há pouco mais de quarenta e cinco anos, maior importância passou a ser concedida à toxoplasmose, pois os conhecimentos adquiridos sobre ela demonstraram, de maneira clara, que tal enfermidade é realmente um problema comum na sociedade e considerado um grave malefício para a saúde humana, gerando lesões sistêmicas e deformidades congênitas. A transmissão ocorre através da ingestão de oocistos e cistos oriundos de animais parasitados, bem como pela via transplacentária (CIMERMAN \& CIMERMAN 1999).

No Brasil, estima-se que aproximadamente $60 \%$ da população adulta tenha entrado em contato com o parasita (GUIMARÃES et al., 1993) e, mundialmente, estima-se que meio bilhão de indivíduos possuem anticorpos contra o T. gondii (SHARMA, 1990).

O estudo da epidemiologia da toxoplasmose determina as formas de ocorrência dessa enfermidade em condições naturais, indicando os fatores que empreendem aqueles que costumam albergar o parasita, visando à prevenção da infecção em seres humanos (CIMERMAN \& CIMERMAN, 1999).

Estudo realizado pelo Serviço de Pesquisas Econômicas do Departamento de Agricultura dos Estados Unidos demonstrou que pelo menos metade dos casos de toxoplasmose ocorre através do manuseio e ingestão de vísceras ou carnes contendo cistos teciduais, constituindo, assim, a principal via de transmissão da toxoplasmose, tanto em animais como no homem, pois os cistos permanecem viáveis em tecidos mantidos em refrigerador, à temperatura de, aproximadamente, $4^{\circ} \mathrm{C}$, por um período de trinta dias. Em regiões onde o consumo desse tipo de alimentação não é usualmente realizado, acredita-se que a infecção humana se mantém por meio da ingestão dos oocistos (JONES et al., 2001).

O diagnóstico laboratorial da toxoplasmose é de grande importância, uma vez que a infecção, tanto no homem como nos animais domésticos e silvestres, pode assumir quadros clínicos facilmente confundidos com uma gama enorme de outras enfermidades, dificultando a tomada de medidas específicas de tratamento e controle.

O diagnóstico sorológico geralmente é estabelecido através da pesquisa de anticorpos antitoxoplasma no soro pelas reações de SABIN-FELDMAN, imunofluorescência indireta (IFA), aglutinação em látex (LAT), e o teste imunoenzimático (ELISA) (GERMANO, 1985).
Diante do crescimento e da importância da caprinocultura na região para o desenvolvimento socioeconômico, principalmente para as populações rurais, através do fornecimento de proteínas animais (carne e leite), pode-se avaliar que a toxoplasmose é um problema emergente a ser considerado na criação nacional, em virtude dos desdobramentos econômicos para essa atividade pecuária e dos riscos potenciais inerentes a essa zoonose para a saúde pública.

Nesse contexto, o estudo da toxoplasmose entre esses animais é relevante, dados os distúrbios da esfera reprodutiva, principalmente o aborto, que pode ocorrer em matrizes de todas as idades com a possibilidade de repetição em gestação subsequente, resultando em perdas econômicas. Há também a possibilidade de transmissão do agente para o homem, seja pelo consumo da carne ou pela ingestão de leite de animais infectados, no caso dos caprinos.

Em virtude do exposto, objetivou-se a realização da pesquisa sobre presença de anticorpos antiToxoplasma gondii em rebanhos caprinos no município de São Luís, MA.

\section{MATERIAL E MÉTODOS}

Caracterização da área

O município de São Luís, (MA) ocupa uma área de $980 \mathrm{~km}^{2}$ e está localizado no Nordeste do Brasil, com uma população aproximada de 978.824 mil habitantes. Possui um rebanho de aproximadamente 185 cabeças de caprinos (AGED 2007), distribuídos em 22 propriedades. Esse número provavelmente é maior, em virtude da grande valorização na criação de caprinos em todo o Brasil.

Foram colhidas amostras de sangue $(5 \mathrm{~mL}) \mathrm{de}$ 92 caprinos, escolhidos aleatoriamente entre machos e fêmeas de faixas etárias distintas, em tubos de ensaio (Vacutainer) individuais sem EDTA, devidamente identificados e acondicionados a $-20^{\circ} \mathrm{C}$ em microtubos plásticos (Ependorf) até a realização dos exames.

O processamento das amostras realizou-se no Laboratório de Patologia Clínica da Universidade Estadual do Maranhão.

A detecção de anticorpos anti-Toxoplasma gondii foi realizada através do método sorológico ELISA indireto (Enzime Linked Immunosorbent Assay), se- 
gundo CAVALCANTE (2004b), tendo sido adquiridos kits comerciais para a realização dos testes. Cada kit possui uma placa com 96 orifícios, sendo quatro utilizados para controles positivos e negativos e 92 para a reação das amostras. Cada amostra foi processada em duplicata. Por fim, realizou-se a leitura da reação de absorbância no leitor ELISA BIO - RAD, na Universidade Federal do Maranhão.

Aplicou-se questionário contendo dezesseis questões fechadas, com vistas à obtenção de informações da propriedade tais como: fonte de água, instalações, manejo alimentar, sanitário e reprodutivo, tipo de exploração, presença de felinos, e dados individuais de cada animal (raça, sexo e faixa etária).

Os dados foram analisados por meio do programa Epi Info 3.5.1 e submetidos aos testes Qui-quadrado $\left(\mathbf{x}^{2}\right)$ e Teste Exato de Fisher.

Todas as discussões foram realizadas ao nível de 5\% de significância.

\section{RESULTADOS E DISCUSSÃO}

Verificou-se que, dos 92 soros analisados, 34 $(36,95 \%)$ foram soropositivos e $58(63,05 \%)$ soronegativos (os resultados estão apresentados no Gráfico 1 e Tabelas 1 e 2). Esses resultados foram superiores aos obtidos por CAVALCANTE et al. (2004), que, utilizandose da mesma prova sorológica, estimaram prevalência de 25,1\% em rebanhos caprinos no estado do Ceará.

A prevalência também foi superior à encontrada por MEIRELES (2001), que registrou 17\% de soropositividade em Botucatu, São Paulo. Entretanto, o resultado foi inferior ao estudo realizado por CARNEIRO (2006), que verificou uma prevalência de $42,8 \%$ dos soros caprinos analisados, em Minas Gerais, também utilizando o método sorológico ELISA.

Em relação às propriedades de rebanhos caprinos pesquisadas, verificou-se soropositividade em oito $(80 \%)$ das dez propriedades do município de São Luís, MA.

Não houve diferenças significativas $(\mathrm{p}<0,05)$ na frequência do $T$. gondii, com relação ao sexo e faixa etária dos caprinos, porém outros fatores obtiveram associação significativa, sendo que estes podem ser considerados fatores de risco, tais como: condições de estocagem de alimento, tipo de exploração, tipo de alimento e destino do material abortado (Tabela 1).

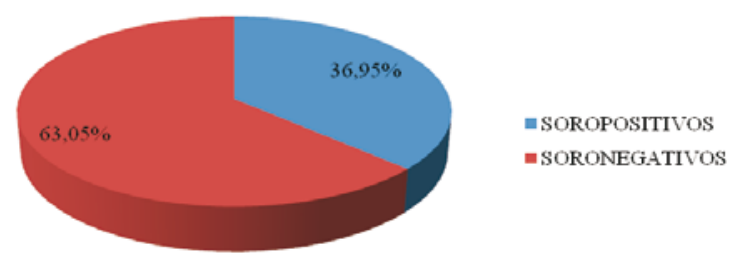

GRÁFICO 1. Soroprevalência de Toxoplasma gondii no município de São Luís, MA.

De acordo com a Tabela 1, em relação às condições de estocagem de alimento, das vinte e quatro consideradas ruins, quatorze $(15,3 \%)$ foram soropositivas para $T$. gondi, demonstrando associação significativa $(\mathrm{p}<0,05)$.

O tipo de exploração implantado nas propriedades também obteve associação significativa ( $p$ $=0,0478)$, merecendo maior atenção por parte dos produtores. Apesar de a maior parte ser destinada ao leite, aquelas exploradas para corte apresentaram um percentual significativo, já que, num total de dezenove animais, onze $(57,89 \%)$ foram soropositivos.

A frequência de toxoplasmose também está associada ao tipo de alimento, apresentando resultados de $58,33 \%$ de soropositividade, ou seja, quatorze dos vinte e quatro animais submetidos à alimentação com forragem $(\mathrm{p}=0,0154)$, considerando que o fornecimento apenas de forragem como fonte de alimentação oferecem risco, por serem uma fonte de infecção por T. gondii. Vale notar que a forma de oocisto, liberada no ambiente, principalmente no que se refere às forragens e locais de pastagem, encontra condições ideais de temperatura e umidade ao desenvolvimento para a forma de oocisto esporulado (infectante), sendo assim um fator de risco aos animais que são submetidos a esse tipo de alimento.

O destino do material abortado também é um fator relevante encontrado neste estudo, já que nenhum dos produtores executa um destino adequado para esse material (incineração). Eles apenas jogam fora ou enterram, o que muitas vezes não elimina a presença do fator de risco $(\mathrm{p}=0,0154)$.

Apesar de não terem sido encontradas associações significativas para as demais variáveis estudadas, vale ressaltar a importância e a devida atenção que 
devem ser dadas a elas. Leva-se em consideração o papel que assumem para transmissão e o fato de estarem associadas ao ciclo biológico do parasita. Citem-se como exemplos a fonte de água da propriedade e a presença de gatos ou outros animais silvestres, bem como o acesso à água ou alimento que será fornecido aos animais.

TABELA 1. Distribuição das variáveis analisadas de caprinos do município de São Luís, MA, relacionados com a propriedade; existência de aprisco; fonte de água da propriedade; destino do material abortado; sistema de criação; tipo de exploração; tipo de alimento; presença de gatos ou outros animais na propriedade; acesso de gatos à água ou ao alimento na baia; ocorrência de aborto e condições de estocagem de alimento.

\begin{tabular}{|c|c|c|c|c|c|c|c|}
\hline \multirow[t]{2}{*}{ Variáveis } & \multicolumn{2}{|c|}{ Soropositivos } & \multicolumn{2}{|c|}{ Soronegativos } & \multicolumn{2}{|c|}{ Total } & \multirow[t]{2}{*}{$\mathrm{p}$} \\
\hline & $\mathrm{N}$ & $\%$ & $\mathrm{~N}$ & $\%$ & $\mathrm{~N}$ & $\%$ & \\
\hline \multicolumn{8}{|l|}{ Existência de aprisco } \\
\hline $\operatorname{Sim}$ & 33 & 35,9 & 59 & 64,1 & 92 & 100,0 & \\
\hline Não & - & - & - & - & - & - & \\
\hline \multicolumn{8}{|c|}{ Fonte de água da propriedade } \\
\hline Tratada & 20 & 21,8 & 49 & 53,3 & 69 & 75,0 & \\
\hline Poço artesiano & 10 & 10,9 & 7 & 7,6 & 17 & 18,5 & 0,3612 \\
\hline Açude & 3 & 3,2 & 3 & 3,2 & 6 & 6,5 & \\
\hline \multicolumn{8}{|c|}{ Condições de estocagem de alimento } \\
\hline Boa & 19 & 20,6 & 49 & 53,2 & 68 & 73,9 & $0,0154 *$ \\
\hline Ruim & 14 & 15,3 & 10 & 10,9 & 24 & 26,1 & \\
\hline \multicolumn{8}{|l|}{ Sistema de criação } \\
\hline Extensivo & 2 & 2,2 & 2 & 2,2 & 4 & 4,3 & \\
\hline Semiconfinamento & 23 & 25,0 & 31 & 33,7 & 54 & 58,7 & 0,4751 \\
\hline Confinamento & 8 & 8,6 & 26 & 28,3 & 34 & 37,0 & \\
\hline \multicolumn{8}{|l|}{ Tipo de exploração } \\
\hline Leiteira & 22 & 24,0 & 51 & 55,4 & 73 & 79,3 & $0,0478^{*}$ \\
\hline Corte & 11 & 12,0 & 8 & 8,6 & 19 & 20,7 & \\
\hline Mista & - & - & - & - & - & - & \\
\hline \multicolumn{8}{|l|}{ Tipo de alimento } \\
\hline Forragem & 14 & 15,2 & 10 & 10,9 & 24 & 26,1 & $0,0154 *$ \\
\hline Forragem + concentrado & 19 & 20,6 & 49 & 53,3 & 68 & 73,9 & \\
\hline \multicolumn{8}{|c|}{$\begin{array}{l}\text { Presença de gatos ou outros } \\
\text { animais na propriedade }\end{array}$} \\
\hline Sim & 22 & 24,0 & 36 & 39,0 & 58 & 63,0 & 0,7540 \\
\hline Não & 11 & 12,0 & 23 & 25,0 & 34 & 37,0 & \\
\hline \multicolumn{8}{|c|}{$\begin{array}{l}\text { Acesso de gatos à água ou ao alimento } \\
\text { na baia }\end{array}$} \\
\hline $\operatorname{Sim}$ & 22 & 24,0 & 36 & 39,0 & 58 & 63,0 & 0,7540 \\
\hline Não & 11 & 12,0 & 23 & 25,0 & 34 & 37,0 & \\
\hline \multicolumn{8}{|l|}{ Ocorrência de aborto } \\
\hline Sim & 31 & 33,7 & 56 & 60,9 & 87 & 94,6 & 0,7784 \\
\hline Não & 2 & 2,2 & 3 & 3,2 & 5 & 5,4 & \\
\hline \multicolumn{8}{|c|}{ Qual o destino do material abortado } \\
\hline Enterra & 19 & 20,7 & 49 & 53,3 & 68 & 74,0 & $0,0154 *$ \\
\hline Incinera & - & - & - & - & - & & \\
\hline Joga fora & 14 & 15,2 & 10 & 10,8 & 24 & 26,0 & \\
\hline
\end{tabular}

(*) Associação significativa $(\mathrm{p}<0,05)$ ao teste do Qui-quadrado. 
TABELA 2. Distribuição das variáveis individuais de caprinos analisados do município de São Luís, MA: faixa etária, raça e sexo

\begin{tabular}{|c|c|c|c|c|c|c|c|}
\hline \multirow[t]{2}{*}{ Variáveis } & \multicolumn{2}{|c|}{ Soropositivos } & \multicolumn{2}{|c|}{ Soronegativos } & \multicolumn{2}{|c|}{ Total } & \multirow[t]{2}{*}{$\mathrm{p}$} \\
\hline & $\mathrm{N}$ & $\%$ & $\mathrm{~N}$ & $\%$ & $\mathrm{~N}$ & $\%$ & \\
\hline \multicolumn{8}{|l|}{ Faixa etária } \\
\hline$<1$ ano & 10 & 10,8 & 20 & 21,8 & 30 & 32,6 & 0,9037 \\
\hline$>1$ ano & 23 & 25,0 & 39 & 42,4 & 62 & 67,4 & \\
\hline \multicolumn{8}{|l|}{ Raça } \\
\hline Mestiço & 20 & 21,8 & 26 & 28,2 & 46 & 50,0 & 0,1921 \\
\hline Puro & 13 & 14,1 & 33 & 35,9 & 46 & 50,0 & \\
\hline Anglo Nubiano & 5 & 10,9 & 9 & 19,7 & 14 & 30,4 & \\
\hline Parda Alpina & 2 & 4,3 & 14 & 30,4 & 16 & 34,8 & \\
\hline Saanen & 6 & 13,0 & 10 & 21,7 & 16 & 34,8 & \\
\hline \multicolumn{8}{|l|}{ Sexo } \\
\hline $\mathrm{F}$ & 24 & 26,1 & 46 & 50,0 & 70 & 76,0 & 0,7564 \\
\hline M & 9 & 9,8 & 13 & 14,1 & 22 & 24,0 & \\
\hline
\end{tabular}

(*) Associação significativa $(\mathrm{p}<0,05)$ ao teste do Qui-quadrado.

\section{CONCLUSÕES}

Os dados obtidos neste estudo permitem concluir que não houve diferenças significativas na frequência do T. gondii, com relação ao sexo e faixa etária dos caprinos, porém outros fatores determinaram associação significativa, sendo considerados fatores de risco, tais como condições de estocagem de alimento, tipo de exploração, tipo de alimento e destino do material abortado.

Com relação às variáveis, é importante que se apliquem medidas que visem o melhoramento genético e manejo sanitário, para que se evite a infecção de caprinos.

Estudos adicionais são necessários para determinar a prevalência de $T$. gondii na carne e no leite dos caprinos, pois o índice desse coccídio vem aumentando assustadoramente na população humana.

\section{REFERÊNCIAS}

ACHA, P. N.; SZYFRES, B. Toxoplasmosis. In: Zoonosis y enfermedades transmisibles comunes al hombre $y$ as los animales. Washington: Organización Panamericana de la Salud, 1986. p. 646-658.

AMATO NETO, V.; MEDEIROS, E. A. S.; LEVI, G. C.; DUARTE, M. I. S. D. Toxoplasmose. 4. ed. São Paulo: Sarvier, 1995. $154 \mathrm{p}$.
CAMARGO, M. C. V.; CHIARI, C. A.; ANTUNES, C. M. F. Importância dos animais domésticos como fonte de infecção do T. gondii para o homem: importância dos animais domésticos como fonte de infecção do T. gondii para o homem. Revista da Sociedade Brasileira de Medicina Tropical, v. 28, n. 3, p. 211-214, 1995.

CARNEIRO, A. C. A. V. Soro-epidemiologia da toxoplasmose caprina e ovina no Estado de Minas Gerais. 2006. Dissertação (Mestrado em Parasitologia) - Instituto de Ciências Biológicas, Universidade Federal de Minas Gerais, BH, 2006.

CAVALCANTE, A. C. R. Toxplasmose caprina no Ceará: soroepidemiologia e caracterização de cepas de Toxoplasmas gondii. 2004. 129 f. Tese (Doutorado em Parasitologia) - Instituto de Ciências Biológicas, Universidade Federal de Minas Gerias, BH, 2004.

CHIARI, C. A.; NEVES, D. P. Toxoplasmose humana adquirida através da ingestão de leite de cabra. Memórias do Instituto Oswaldo Cruz, n. 3, v. 79, p. 337-340, 1984.

CIMERMAN, B.; CIMERMAN, S. Parasitologia humana e seus fundamentos gerais. In: AMATO NETO, V.; MARCHI, C.R. Toxoplasmose. São Paulo: Atheneu, 1999. p. 151-181.

CORCUERA, M. T.; LOZANO, J.; LOPEZ, R. F. Estudio comparativo de las distinctas técnicas serologicas utilizadas para el diagnostico de la toxoplasmosis. Revista de Sanitarismo e Higiene Pública, n. 55, p. 1045-1059, 1981. 
DUBEY, J. P. Epizootic toxoplasmosis associated with abortion in dairy goats in Montana. American Veterinary Medical Association, v. 178, p. 661-670, 1981 b.

DUBEY, J. P Toxoplasma induced abortion in dairy goats. Journal American Veteterinary Medical Association, v. 178, p. 671-674, 1981a.

DUBEY, J. P.; HOOVER, E. A. Attempted Transmission of Toxoplasma gondii Infection from pregnant cats to their kittens. American Veteterinary Medical Association, v. 170, p. 538$540,1977$.

DUBEY, J. P.; LINDSAY, D. S.; SPEER, C. A. Structures of Toxoplasma gondii: tachyzoites, bradyzoites, sporozoites and biology and development of tissue cysts. Clinical Microbiology Reviews, v. 11, n. 2, p. 267-299. 1998.

DUBEY, J. P.; SWAN, G. V.; FRENKEL, J. K. A simplified method for isolation of Toxoplasma gondii from the faeces of cats. Journal Parasitology, v. 58, p. 1005-1006, 1972.

DUBEY, J. P. Toxoplasmosis: an overview. Southeast Asian. Journal of Tropical Medicine and Public Health, v. 22, p. 88119, 1991.

DUBEY, J. P.; THULLIEZ, P. Persistence of tissue cysts in edible tissues of cattle fed Toxoplasma gondii oocysts. American Journal of Veterinary Research, v. 54, n. 2, p. 270-273, 1993.

DUBEY, J. P.; WEIGEL, R. M.; SIEGEL, A. M.; THULLIEZ, P.; KITRON, U. D.; MITCHELL, M. A.; MANNELLI, A.; MATEUSPINILLA, N. E.; SHEN, S. K.; KWOK, O. C. H.; TODD K. S. Sources and reservoirs of Toxoplasma gondii infection on 47 swine farms in Illiniois. Journal Parasitology, v. 81, p. 723-729, 2003.

FELDMAN, H.; MILLER, L. Soroblogical study of Toxoplasmosis prevalence. American Journal of Higiene, v. 64, p. 320-335, 1956.

GERMANO, P. M. L.; ERBOLATO, E. B.; ISHIZUKA, M. M. Estudo Sorológico da toxoplasmose canina, pela prova de Imunofluorescência indireta, na cidade de Campinas, 1981. Revista da Faculdade de Medicina Veterinária e Zootecnia, v. 22, n. 1, p.53-58, 1985.
GONDIM, L. F. P. et al. Serological survey of antibodies to Toxoplasma gondii in goats, sheep, cattle and water buffaloes in Bahia State, Brazil. Veterinary Parasitology, n. 3, v. 82, p. 273-276, 1999.

GUIMARÃES, A. C. S.; KAWARABAY, M. BORGES, M. M.; TOLEZANO, J. E.; ANDARADE JR. H. F. Regional variation in toxoplasmosis seronegativity in the São Paulo metropolitan region. Revista Instituto de Medicina Tropical de São Paulo, v. 35 n. 6, n. p. 479-483, 1993.

JONES, J. L.; KRUSZON-MORAN, D.; WILSON, M.; MCQUILLAN, G.; NAVIN, T.; MCAULEY, J. B. Toxoplasma gondii infection in the United States: seroprevalence and risk factors. American Journal Epidemiology. v. 154, n. 4, p. 357-365, 2001 .

MACHADO, T.M.M.; LIMA, J.D. Frequência de anticorpos antiToxoplasma gondii em caprinos criados sob diferentes formas de exploração no Estado de Minas Gerais. Arquivos Brasileiros de Medicina Veterinária e Zootecnia, n. 2, v. 39, p. 255-264, 1987.

MEIRELES, L. R. Estudo das fontes de infecção da toxoplasmose humana em diferentes localidades do Estado de São Paulo. 2001. Dissertação (Mestrado em Ciências: Parasitologia) - Instituto de Ciências Biomédicas, Universidade de São Paulo, SP, 2001.

NICOLLE, C.; MANCEAUX, L. Sur une infection à corps de Leishman (ou organismes voisins) du gondii. Comptes Rendus Hebdomadaires des Séances de L'Académie des Sciences, v. 174, p. 763-766, 1909.

PIZZI, H. L. Toxoplasmosis. 1. ed. Argentina: Rhône Poulenc Rorer Argentina, 1997. $91 \mathrm{p}$.

SHARMA, S. D. Immunology of toxoplasmosis. In: DAVID, J. W. Modern parasite biology: cellular, immunological and molecular aspects. New York: WH Freeman, 1990. p. 184-99.

SIDRA - Sistema IBGE de recuperação automática, 2005. Disponível em <http://www.sidra.ibge.gov.br/bda/Tabela/protabl. $\operatorname{asp} ? \mathrm{z}=\mathrm{t} \& \mathrm{o}=20 \& \mathrm{i}=\mathrm{P}>$. Acesso em: 20 abr. 2007. 


\section{APÊNDICE}
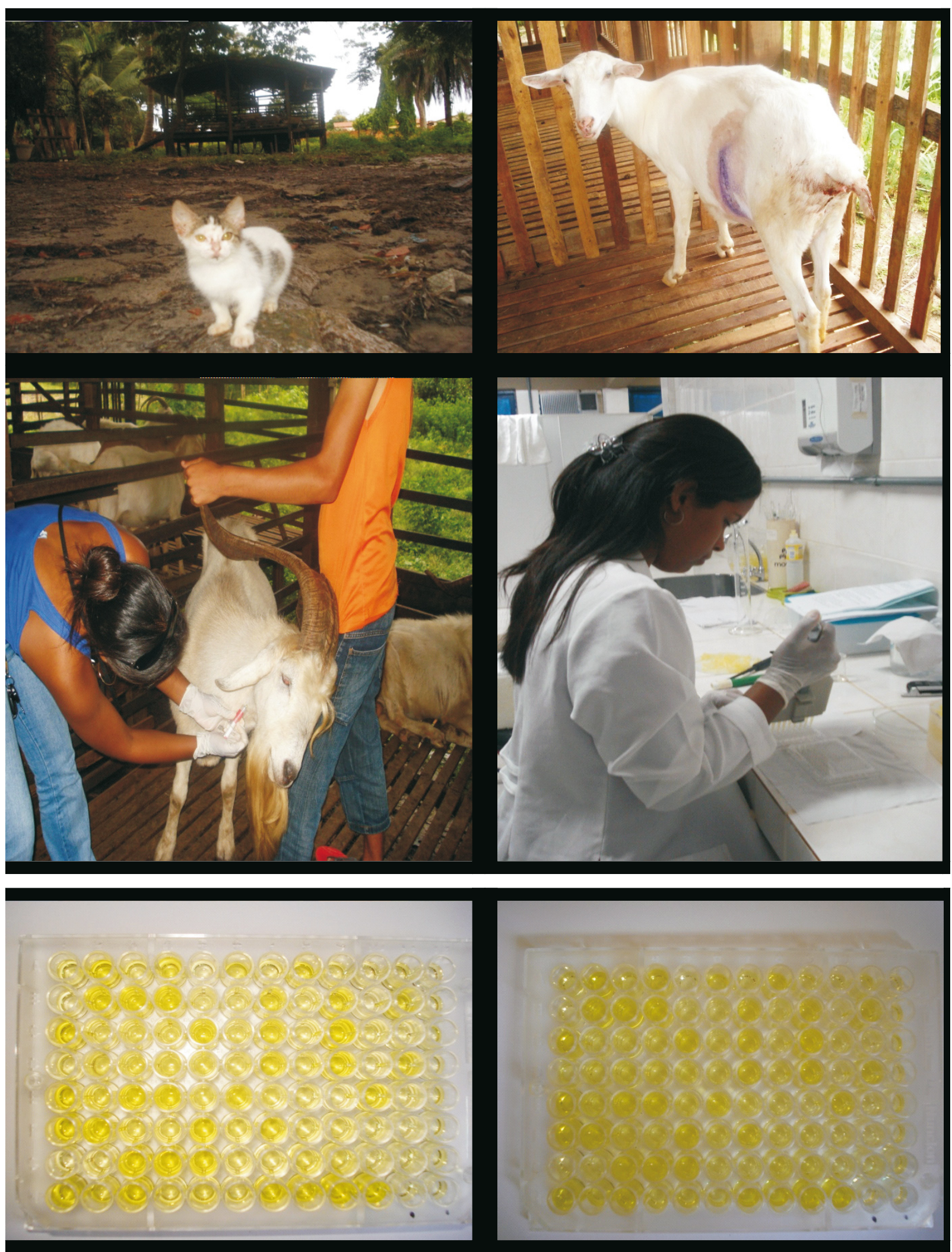

FIGURA 1. Avaliação das propriedades, colheita e processamento do material, e resultado do teste diagnóstico. 
INQUÉRITO SOROLÓGICO DE ANTICORPOS ANTI-Toxoplasma Gondii EM REBANHOS CAPRINOS E OVINOS NO MUNICÍPIO DE SÃO LUÍS-MA

Propriedade:

Distrito:

Data:

Endereço:

01 - Fonte de água da propriedade?

Tratada Poço artesiano Açude

02 - Presença de aprisco?

Sim Não

03 - Presença de gatos?

Sim Não

04 - Acesso de gatos à água e /ou alimentos?

Sim Não

05 - Fonte de alimento:

Forragem Concentrado Forragem + concentrado Suplemento

06 - Condição de estocagem dos alimentos:

Boa Ruim

07 - Sistema de exploração:

Confinamento Semiconfinamento Extensivo

08 - Tipo de exploração:

Carne Leite Mista

09 - Ocorrência de abortos na propriedade?

Sim Não

10 - Destino do material abortado:

Joga fora Incinera Enterra

\section{INQUÉRITO SOROLÓGICO DE ANTICORPOS ANTI-Toxoplasma Gondii EM REBANHOS CAPRINOS E OVINOS NO MUNICÍPIO DE SÃO LUÍS-MA}

Propriedade:

Distrito:

Data:

Endereço:

01 - Identificação do animal (№):

$\mathrm{N}^{\mathrm{o}}$. Tubo:

02 - Idade: $\quad>1$ ano $\quad<1$ ano

03 - Sexo: $\quad$ M-Macho F-Fêmea

04 - Raça: Puro___ Mestiço

05 - Pelagem:

06 - Aptidão: Corte Leite Mista 